\title{
Distance learning: integration of media education into teaching of social-pedagogical disciplines
}

\author{
Elena Muryukina ${ }^{1,2, *}$, Marina Pevneva ${ }^{1,3}$, Tatiana Poliakova ${ }^{4}$ \\ ${ }^{1}$ Don State Technical University, 1, Gagarina pl., Rostov-on-Don, Rostov Oblast, 344010, Russia \\ ${ }^{2}$ Moscow Pedagogical State University, MPGU, 1/1, Malaya Pirogovskaya Str., Moscow, 119991, \\ Russia \\ ${ }^{3}$ Rostov State Medical University, 29, Nakhichevansky per., Rostov-on-Don, 344022, Russia \\ ${ }^{4}$ Moscow Polytechnic University, 38, B.Semenovskaya Str., Moscow 107023, Russia
}

\begin{abstract}
New time challenges cause new contradictions that are peculiar for educational environment in Russia and they require instant solutions. We have identified the contradictions which defined our target to determine the techniques and methods of distance education for students of pedagogical specializations based on practice-oriented approach, implementation of media educational technologies into the preparation of university students aimed at the development of knowledge, competencies and skills in distance learning in different types of educational institutions. Media educational technologies are conditioned by general pedagogical and didactic principles and the choice of pedagogical methods directly depends on the content of educational discipline, conditions of its implementation and other factors. Media educational technologies used for the completion of social-pedagogical disciplines for university students consist of creative and game tasks. Using them it is essential to consider special features of various media and the target of the lesson. Practice is another relevant purpose in the process of distance learning. We believe that this problem will be dominating in the nearest future as practice in distance learning is focused on by higher education institutions. In this article some techniques and types of this practical training are presented being shaped by the format of distance learning. During various practices the students of pedagogical specializations will be able not only to prepare for their future work but also to assist subject teachers, social pedagogues in schools and to make considerable contributions in this work.
\end{abstract}

\section{Introduction}

Nowadays Russia (like all the global community) faced the epidemic challenge (coronavirus). Our country has to take this challenge with dignity and to take adequate measures and to work out prospective ideas and ways to overcome suchlike risks. Coronavirus revealed a lot of problems connected with the full functionality of pedagogical system.

\footnotetext{
${ }^{*}$ Corresponding author: murjukina@ya.ru
} 
We are focusing our attention on the educational system in Russia. In spring 2020 Russian educational institutions of all types (nursery and secondary schools, additional educational units, colleges and universities) were switched to online education. Studying the practical issues of this approach to education revealed that techniques, technologies and methods are not sufficiently developed in Russian pedagogical science, i.e. methods aimed at implementation of the variety of pedagogical activities with students. Based on it we have found out the following contradictions:

- between the sufficient level of education technique elaboration in online format and the absence of theoretical grounds, methods, patterns and technologies to complete other tasks of pedagogical system - educational and developing;

- between the necessity to apply distance learning in the context of practice-based approach (for example, for students of pedagogical specializations) and the absence of technologies to complete educational programs conforming to the standards of this approach;

- between the necessity to provide practice-oriented assistance for teachers and potential that is introduced by the institutions training students of pedagogical departments;

- between the existing system of training teachers in universities and the requirements to use media education technologies in distance learning for school students forwarded by the modern life conditions and the threat for humanity (for example, COVID-19).

Identified contradictions define the task for our research which aims at revealing techniques and methods for implementation of distance learning for the students of pedagogical specializations in the context of practice-oriented approach; incorporation of media education technologies in training students of pedagogical specializations which generate knowledge, skills and competencies while distance learning in educational institutions of different types.

The syllabus of Bachelor program 44.03.01 Pedagogical training for the specialization "Social pedagogy in education" contains the following social-pedagogical disciplines:

- The history of social pedagogy;

- The social protection of childhood;

- The pedagogy of social upbringing;

- Social-pedagogical modelling;

- Pedagogical activity in social sphere;

- Concepts of social pedagogy;

- Social work with young people and others.

The completion of aforementioned disciplines in distance learning will be more effective if media education technologies are applied. We are sure that the synergy of these technologies will allow solving not only the educational task but also pedagogical and developing tasks with students. The solution of these tasks seems to be possible for us when integrating various media education technologies.

\section{Materials and methods}

The materials of this research are media education technologies; disciplines in the syllabus of Bachelor program 44.03.01 "Social pedagogy in education" realized in Don State Technical University.

We use the following approaches and methods:

- activity approach. A.N. Leontiev wrote that to acquire the achievements of human culture every new generation had to fulfill the activity similar (but not identical) to that one which is the background for these achievements. Therefore the application of this approach 
becomes indispensable for the implementation of media educational technologies in teaching social-pedagogical disciplines;

- practice-oriented approach which targets at intensification of the search, obtaining and accumulation of new knowledge and skills for generation of particular competencies of students;

- interdisciplinary approach which will allow to present general scientific methodology where the processes of scientific knowledge in specific fields and their integration are combined.

Consequently, in our opinion, the suggested approaches will contribute to conduct the research on the topic effectively and with a high degree of quality. Supposed methods are studying the scientific literature, pedagogical and comparative analysis, synthesis, generalization etc.

\section{Results}

The relevance of the problem of this research is conditioned by the following factors:

- understanding the requirements of Russian modern society and proactive elaboration of possible tasks in distance learning together with media education technologies;

- low level of advances in the field of distance learning using media education technologies whereas its importance is obvious; synergy of media education into the teaching of social-pedagogical disciplines represents excellent opportunities for the fulfillment of all the scope of pedagogical tasks: training, developing and counselling; creation of conditions and mechanisms to implement the distance learning for students in the context of practice-oriented approach;

- urgent necessity to develop competencies of students who study pedagogy as a major in educational institutions of different types for future professional application;

- opportunity to achieve the target of student's personality development and his competencies connected with media and information literacy.

We are using the interdisciplinary approach based on pedagogy, communication science, social philosophy, sociology and others.

The problems of communication science are actively being studied in Russia and abroad. For example, G.P. Bakulev [1], V.B. Kashkin [12] and others develop the theory of communication as a modern field in scientific society considering the ways to implement the theory of communication into different sciences.

The development of distance learning problems in Russian pedagogical science was represented by such filed as media education science. Almost 100 years the media pedagogues have been studying different aspects of the interaction of new generations with media. This was reflected in such pedagogical, psychological, social and cultural studies by Guo Ming Chen [9], R. Kubey [13], W.J. Potter [18], K. Tyner [20] etc.

Russian media pedagogues A.V. Fedorov, A.A. Levitskaya, O.I. Gorbatkova [4] describe the relationships in schools and universities in the context of movies on this topic.

C. Feilitzen [5] researches the influence of mediated violence reflected in mass media. The works of C. Ferguson, J. Kilburn [6], C. Gálik [7, 8] disclose the risks for health via watching films containing the scenes of violence.

Special attention is paid to social-pedagogical work with school students in the context of their interaction with media space, ethical and legal perspective of school consultants to prevent violence in schools by A. Hermann, A. Fin [10], L.R. Huesmann, J.F. Moise, C.L. Podolski [11], etc. J. Lewis studies the dependence of antisocial behavior on media violence.

L.C. Zaznobina [21] and many others dealt with the problem of media integration into the school subjects (chemistry, literature, etc.) using curriculum and extra curriculum 
activities (clubs, optional subjects, etc.) The scientist created the programs for different age groups of school students that were implemented in 1-11 grades. Russian scientists V.S. Basyuk, E.A. Bayer, M.V. Zaluzhnaya [2] also discuss modelling of activities of the institutions of state support of the childhood in order to strengthen family ties using integrational approach.

More often media pedagogues address the problems of training future teachers for professional activities. Therefore E.V. Muryukina, V.M. Voychenko [15] investigate techniques, methods and tools of media education implementation into educational institutes. They point out that it is effective to use creative and heuristic tasks based on media education technologies. I.V. Zhilavskaya [22] outline the risks of internet communication content for young people, also she considers the problems of integration of internet journalism and media education into the training activities of journalist departments.

Thus we can emphasize that media education has a lot of Russian and foreign followers. The problems of distance learning were studied by E.S. Polat [17]. His monograph and articles are well-known for the scientific society. He presents the classification of distance learning models, the criteria for measuring its effectiveness and some other ideas. It is definitely important to mention that E.S. Polat [17] was the first to study this trend in $90 \mathrm{~s}$ being aware of its relevance in future.

Nowadays the problems of distance learning attract the scientists who strive to give reasons and arguments supporting distance learning as a new type of education. It is noted that the effectiveness of distance learning is determined by the use of pedagogical technologies that are the core component in the design and implementation of online courses. It can be stated that distance learning is a separate type of education characterized by the substantial differences that cannot be applied in traditional studies.

We assume that distance learning needs to fulfill the requirements of the specialization of training program in higher education institutions. Therefore for the achievement of this target it is mandatory to create techniques for students' training in the context of practiceoriented approach and to implement distance learning using media education technologies in various educational institutions.

We emphasize that Russian science lacks theoretical grounds for the development of distance learning based on the specialization of university programs, there are no techniques and technologies which enable the use of distance learning corresponding all the objectives that must be considered within the pedagogical system.

\section{Discussion}

Media education technologies are defined by general pedagogical didactic principles. It is possible to claim that the choice of pedagogical methods directly depends on the peculiarities of the content of a discipline, conditions of its fulfilment and other factors.

Media education technologies, used for the completion of disciplines of socialpedagogical specializations in universities, include creative and game tasks. The determinant factor in choosing technologies is media texts (printed variety, photographs, audiovisual aids, computer technologies, etc.).

While applying technologies for teaching social-pedagogical disciplines to university students it is significant to account for specified topics of different media and the targets of the lesson.

We present the following media education technologies which can be used in distance learning of social-pedagogical disciplines:

- Oral Journal. Students prepare presentations on the topics connected with socialpedagogical problems. The journal issues can cover various topics: "Pedagogical 
technologies of social upbringing", "Social-pedagogical modelling”, 'Pedagogical activity in social sphere", "Modern concepts of social pedagogy in Russia and abroad" and others.

- The main work stimulating the scientific and cognitive activity of university students can be based on the lessons that include media sources, for example, review of academic articles in the professional field. Students read scientific literature and then give oral and written reviews, write essays or do creative tasks.

- Mixed logical chains. This media education technology will be effective while working with the group of students at online classes. This technology promotes students' activity, involves them into the lesson, increases their interest and creates motivation for studies. For example, the above mentioned technology can be applied in practical classes of the discipline "Pedagogy of social upbringing". The students will be offered to watch the film "Chuchelo" by R. Bykov as a media text.

The main steps of the class with media education technologies:

1. The teacher demonstrates five-six separate scenes from the film "Chuchelo" and places them on the screen randomly.

2. The students have to give the correct sequence of the storyline. This concentrates the student's attention, facilitates understanding of the director's concept in the film. Also it is possible to give another task - to create the probable development of events in the film being based on the conditions offered by the director.

Media education technology of a free written task. Limited by time (not more than 5 minutes) the students are requested to write down their ideas that were generated while studying the topic within the discipline "Social-pedagogical modelling". Having completed the task the students read their ideas. There are several options to check this task, for example, to share their ideas with the group, to get the results by the brainstorming method, to outline insecure ideas in an essay and then to check their credibility in the discussion.

Media education technology of exchange studies will be also effective in teaching social-pedagogical disciplines to university students. This method engages students into the role of a teacher and manages the students' activities that aim at studying a media text, a media resource, etc. that correspond the field of studied problems. The students must be divided into groups, each group is given the same text, resource, website, etc. When the groups present the results of their analysis the teacher:

1.reviews the content of the paragraph;

2. compiles questions about the text and asks other groups to answer them;

3. specifies the terms and difficult parts of the text which are incomprehensible for other participants;

4. gives tasks before reading the next paragraph.

Project activity. Media education projects in social-pedagogical disciplines are proved to be an important tool to develop cognitive activities, personal qualities and creativity. Project method, focused on research activity, is targeted at the development of the skill to navigate in media space, to analyze media content critically, to present the results of the research, to use the knowledge of media culture and to acquire new knowledge.

Projects can foster creation and implementation of personal media products (sociopedagogical films, newspapers and commercials), development of scripts, analytical reviews, essays, etc.

Solving the problem of various practice-oriented programs in distance learning is a separate important target. We think this problem will be the leading one as universities assign great importance to practice. We offer some techniques and the ways to solve it.

The students of pedagogical specializations in the period of practice (during distance learning) will be able not only to prepare for their future professional activity but to make considerable contributions and to provide assistance to subject teachers, social pedagogues 
in schools. For instance, we assume that during the practice the university students of pedagogical specializations can perform a given range of tasks. Here are some examples:

- 1-2-year Bachelor students: assistance for subject teacher in the development of online class: creation of presentation, design of topical info visual cards for school students, assessment of homework, etc.

- 3-4-year Bachelor students: creation of lesson task bank, assessment of tests; creation of topical schemes, tables, diagrams and graphs for school students, etc.

-Master Students: conducting lessons in small-size rural schools where there is a lack of teachers; preparation of school students for conferences, etc.

- 1-2-year Bachelor students will also be able to assist social pedagogues in conducting questionnaire surveys, testing school students, processing large amounts of obtained data, conducting primary analysis, etc.

- 3, 4, 5- year students can conduct individual and group classes with school students based on individual plan that is compiled together with the social pedagogue, also they can hold online meetings with the parents of problem school students, analyze the social networks profiles of students with deviant and delinquent behavior, etc.

\section{References}

1. G.P. Bakulev, Mass communication: Western theories and concepts: Textbook for university students (Aspect Press, Moscow, 2005)

2. V.S. Basyuk, E.A. Bayer, M.V. Zaluzhnaya, Modeling of institutions activity government support for childhood to strengthen the family institution based on integrative ones (AzovPrint, Azov, 2017)

3. U. Eco, The Role of the Reader: Exploration in the Semiotics of Texts (Indiana University Press, Bloomington, 2005)

4. A. Fedorov, A. Levitskaya, O. Gorbatkova, A. Mamadaliev, European journal of contemporary education 7(3), 458-464 (2018) DOI: 10.13187/ejced.2018.3.458

5. C. Feilitzen, Influences of Mediated Violence. Children and youth in the digital media culture. Yearbook. From a Nordic Horizon (Nordicom. University of Göteborg, Göteborg, 2010)

6. C. Ferguson, J. Kilburn, The public health risks of media violence: A meta-analytic review. Pediatrics (2009) DOI: 10.1016/j.jpeds.2008.11.033

7. S. Gálik, EJTS European Journal of Transformation Studies 7(2), 33-44 (2019)

8. S. Gálik, Media Education 60(1), 100-106 (2020) DOI: 10.13187/me.2020.1.100

9. Guo Ming Chen, Media Research 3(3), 87 - 103 (2007)

10. M. Hermann, A. Fin, Professional School Counseling 6(1), 46-54 (2002)

11. L.R. Huesmann, J.F. Moise, C.L. Podolski, The effects of media violence on the development of antisocial behavior. In Handbook of antisocial behavior (John Wiley \& Sons, New York, 1997)

12. V.B. Kashkin, Fundamentals of the Theory of Communication: A Brief Course (AST: East-West, M., 2007)

13. R. Kubey, Media Literacy in the Information Age (Transaction Publishers, New Brunswick and London, 2011)

14. J. Lewis, Media, culture and human violence: from savage lovers to violent complexity (Rowman \& Littlefield, 2016)

15. E. Muryukina, V. Voychenko, Media Education 60(3), 499-507 (2020) 
16. M.V. Pevneva, S.V. Maximets, N.V. Toulupchi, Media Education 59(3), 499-507 (2019) DOI: 10.13187Zme.2019.3425 www.ejournal53.com

17. E.S. Polat, M.Yu. Bukharkina, M.V. Moiseeva, A.E. Petrov, New pedagogical and information technologies in education system (Academy, Moscow, 1999)

18. W.J. Potter, Media Literacy (Sage Publication, L.A., 2012)

19. D. Romer, P.E. Jamieson, K.H. Jamieson, Pediatrics 139(2), 2016-2891 (2017)

20. K. Tyner, Media Literacy: New Agendas in Communication (The University of Texas, Routledge, 2010)

21. L.C. Zaznobina, Standards and Monitoring in Education 3, 26-34 (1998)

22. I.V. Zhilavskaya, Risks of Internet Communication of Children and Youth (Moscow, MGPU, 2019) 